\title{
TESTE DE GERMINAÇÃO DE SEMENTES DE Parapiptadenia rigida (BENTH.) BRENAN (FABACEAE) ${ }^{1}$
}

\author{
VITOR HENRIQUE VAZ MONDO², PEDRO HENRIQUE SANTIN BRANCALION${ }^{3}$, SILVIO MOURE CICERO ${ }^{4}$, \\ ANA DIONISIA DA LUZ COELHO NOVEMBRE ${ }^{5}$, DURVAL DOURADO NETO ${ }^{6}$
}

\begin{abstract}
RESUMO - Parapiptadenia rigida (angico vermelho) é uma espécie florestal brasileira que vem sendo utilizada para restauração florestal e para a extração de madeira. No entanto, as informações sobre o teste de germinação para as sementes dessa espécie são escassas, sendo necessários estudos adicionais visando a definição e a padronização de metodologias mais adequadas. Dessa forma, os efeitos de nove intervalos de temperatura, entre $15^{\circ} \mathrm{C}$ e $35^{\circ} \mathrm{C}$, foram avaliados em mesa termogradiente com fotoperíodo diário de 8 horas; além disso, foram analisadas quatro condições de substratos (sobre papel, rolo de papel, entre vermiculita e sobre vermiculita) em germinadores a $25^{\circ} \mathrm{C}$ e $30^{\circ} \mathrm{C}$, com o mesmo fotoperíodo. Os substratos entre e sobre vermiculita foram testados, também, na ausência de luz, na temperatura de $25^{\circ} \mathrm{C}$. Com os resultados obtidos, conclui-se que o teste de germinação de sementes de $P$. rigida deve ser realizado na temperatura de $25^{\circ} \mathrm{C}$, utilizando-se o substrato entre vermiculita, na presença ou ausência de luz.
\end{abstract}

Palavras-chave: espécies florestais, análise de sementes, substratos.

GERMINATION TEST OF SEEDS OF Parapiptadenia rigida (BENTH.) BRENAN (FABACEAE)

\begin{abstract}
Parapiptadenia rigida is a Brazilian tree species that has been used for forest restoration and wood extraction. However, the information available about the germination test with the seeds of this species is scarce, and additional studies are neede define and standardize the most favorable methodologies. Therefore, the effects of nine temperature intervals between $15^{\circ} \mathrm{C}$ and $35^{\circ} \mathrm{C}$ were evaluated in a thermo-gradient table with a daily photoperiod of 8 hours and four substrate conditions (on top of the paper, paper roll, in vermiculite and on top of vermiculite) were analyzed in chambers with the same photoperiod, at $25^{\circ} \mathrm{C}$ and $30^{\circ} \mathrm{C}$. The substrates in and on top of vermiculite were also tested without light, at $25^{\circ} \mathrm{C}$. The results showed that the germination test of $P$. rigida seeds should be carried out at $25^{\circ} \mathrm{C}$, with the substrate in vermiculite, with or without light.
\end{abstract}

Index Terms: forest seeds, seed analysis, substrates.

${ }^{1}$ Submetido em 25/10/2007. Aceito para publicação em 18/06/2008.
22Doutorando em Fitotecnia, ESALQ/USP; bolsista da CAPES; Caixa Postal
09; CEP 13.418-900; Piracicaba, SP; e-mail: vhvmondo@yahoo.com.
br. ' ${ }^{3}$ Doutorando em Fitotecnia, ESALQ/USP; bolsista da CAPES; Caixa
Postal 09; CEP 13.418-900; Piracicaba, SP; e-mail: pedrohsb@yahoo.com.
br ${ }^{4}$ Professor Titular, Departamento de Produção Vegetal, ESALQ/USP; bolsista do CNPq; Caixa Postal 09; CEP 13418-900; Piracicaba, SP; e-mail: smcicero@esalq.usp.br. ${ }^{5}$ Professor Doutor, Departamento de Produção Vegetal, ESALQ/USP; Caixa postal 09; CEP 13.418-900; Piracicaba, SP; e-mail: adlcnove@esalq.usp.br. ${ }^{6}$ Professor Titular, Departamento de Produção Vegetal, ESALQ/USP; bolsista do CNPq; Caixa postal 09; CEP 13.418-900; Piracicaba, SP; e-mail: dourado@esalq.usp.br. 


\section{INTRODUÇÃO}

A espécie Parapiptadenia rigida (Benth.) Brenan (angico vermelho), pertencente à família FabaceaeMimosoideae, é característica e exclusiva da mata latifoliada das bacias dos Rios Paraná, Uruguai e afluentes (Lorenzi, 2002), sendo recomendada para a recuperação de áreas degradadas (Souto, 1984) e para a restauração florestal em áreas de preservação permanente (Durigan e Nogueira, 1990). É uma árvore secundária inicial (Vacaro et al., 1999), decidual, de 20 a $35 \mathrm{~m}$ de altura, com copa corimbiforme composta por folhagem verde-escura e de madeira muito pesada, elástica e bastante durável, o que a torna própria para construções rurais e para a carpintaria (Reitz et al., 1988), sendo também aproveitada em curtumes, por ser rica em tanino (Sakita e Vallilo, 1990).

O estudo de espécies florestais, em análise de sementes, tem merecido atenção no meio científico, visando a obtenção de informações, atualmente escassas, que expressem a qualidade fisiológica das sementes, tanto para sua preservação como para a utilização dessas espécies vegetais com os mais variados interesses. No entanto, poucas espécies florestais nativas do Brasil estão incluídas nas Regras para Análise de Sementes (Brasil, 1992), o que dificulta a realização dos testes de germinação.

As sementes, em geral, apresentam um desempenho variável, quanto a germinação, em diferentes temperaturas e substratos, que são componentes básicos do teste de germinação; assim, o conhecimento da influência desses componentes na germinação de cada espécie é de importância fundamental.

A temperatura é considerada ótima, para a germinação das sementes, quando estas expressam seu potencial máximo de germinação em menor tempo, havendo prejuízos na germinação quando as temperaturas estão acima ou abaixo desse valor ótimo (Popinigis, 1985; Mayer e Poljakoff Mayber, 1989). Para as espécies florestais nativas, a temperatura ótima de germinação situa-se entre $15^{\circ} \mathrm{C}$ e $30^{\circ} \mathrm{C}$, a qual está relacionada, normalmente, às temperaturas da região de origem da espécie na época favorável para a germinação (Andrade et al., 2000). Dessa forma, existem espécies cujo processo germinativo é favorecido por temperatura constante (Varela et al., 1999; Sousa, 2000; Silva, 2001), por alternância de temperatura (Gomes e Bruno, 1992; Santos e Aguiar, 2000; Lopes e Soares, 2003;) e por um intervalo amplo de temperatura (Nassif e Perez, 2000; Silva et al., 2002).

Alcalay e Amaral (1981) e Figliolia et al. (2005) trabalhando com sementes de angico vermelho utilizaram a temperatura de $25^{\circ} \mathrm{C}$ como padrão para o teste de germinação. No entanto, Ramos et al. (1995) afirmaram que o teste de germinação para sementes dessa espécie pode ser conduzido também a $20^{\circ} \mathrm{C}$.

O substrato influencia diretamente na germinação, pois em função de sua capacidade de retenção de água, estrutura e aeração, afeta o fornecimento de água e de oxigênio para as sementes e oferece suporte físico para o desenvolvimento da plântula (Figliolia et al., 1993). Segundo os mesmos autores, na escolha do material para substrato, deve ser considerado o tamanho da semente, sua exigência com relação à água, sensibilidade ou não à luz e a facilidade que este oferece para o desenvolvimento e a avaliação das plântulas. Para as sementes de angico-vermelho os substratos recomendados, segundo Ramos et al. (1995), são vermiculita, areia, papel mata-borrão e papel toalha.

Assim, um outro ponto importante é a interferência da luz na germinação de sementes de algumas espécies. São denominadasfotoblásticaspositivasasespéciesquenecessitam da presença de luz para a germinação de suas sementes, fotoblásticas negativas as que germinam necessariamente na ausência de luz e existem ainda as fotoblásticas neutras ou não fotoblásticas, as quais não apresentam sensibilidade à luz. A classificação das sementes quanto à sensibilidade à luz torna-se então evidente para a condução dos testes de germinação (Villiers, 1972; Marcos Filho, 1986; Mayer e Poljakoff Mayber, 1989; Brasil, 1992).

Assim, a pesquisa objetivou avaliar as condições de temperatura, de substrato e de luz para a condução do teste de germinação para sementes de angico vermelho.

\section{MATERIAL E MÉTODOS}

A pesquisa foi realizada nos Laboratórios de Análise de Imagens e de Análise de Sementes, do Departamento de Produção Vegetal da Escola Superior de Agricultura "Luiz de Queiroz", Universidade de São Paulo, em Piracicaba, SP, no período de maio a julho de 2006.

As sementes de angico-vermelho foram coletadas de sete matrizes localizadas na cidade de Assis-SP, em julho de 2004, constituindo um lote, e foram armazenadas por um ano e oito meses em câmara fria e seca a $10^{\circ} \mathrm{C}$ e $40 \%$ de umidade relativa do ar até a realização dos experimentos.

A caracterização inicial foi realizada por meio da determinação do teor de água, utilizando-se o método de estufa a $105 \pm 3^{\circ} \mathrm{C}$ por 24 horas, e da massa de 1000 sementes, segundo metodologias descritas nas Regras para Análise de 
Sementes (Brasil, 1992).

$\mathrm{O}$ estudo da temperatura foi realizado em uma mesa termogradiente, marca Van den Berg, tipo 890, onde nove intervalos de temperatura, entre $15,0^{\circ} \mathrm{C}$ e $35,0^{\circ} \mathrm{C}$, constituíram os tratamentos, $\mathrm{T} 1$ a T9, com cinco repetições de 10 sementes cada. Em placas de petri, com oito centímetros de diâmetro, foram distribuídas 10 sementes sobre duas folhas de papel mata-borrão previamente umedecidas com quantidade de água equivalente a 2,3 vezes a massa das mesmas.

Após a realização e avaliação do primeiro estudo, foi instalado em germinadores o estudo de substratos. Assim, foram utilizados os substratos entre vermiculita (EV), sobre vermiculita (SV), sobre papel (SP) e rolo de papel (RP), cada um em duas condições de temperaturas, $25^{\circ} \mathrm{C}$ e $30^{\circ} \mathrm{C}$, constituindo oito tratamentos, compostos cada um por oito repetições de 25 sementes.

Os tratamentos sobre vermiculita, entre vermiculita e sobre papel foram acondicionados em caixas plásticas transparentes $(11 \mathrm{~cm} \times 11 \mathrm{~cm} \times 3 \mathrm{~cm})$. O substrato vermiculita foi previamente esterilizado utilizando-se uma estufa a 105 $\pm 3^{\circ} \mathrm{C}$ por 24 horas. Para o tratamento EV distribuiu-se a quantidade de $30 \mathrm{~g}$ de vermiculita sobre a qual as sementes foram semeadas e, em seguida, cobertas por mais $20 \mathrm{~g}$ do mesmo substrato. $\mathrm{O}$ tratamento $\mathrm{SV}$ foi instalado distribuindose $50 \mathrm{~g}$ de vermiculita, sobre a qual as sementes foram semeadas. Após a semeadura, o umedecimento foi realizado de maneira que se obtivesse $70 \%$ da capacidade de retenção de água do substrato, conforme as Regras para Análise de Sementes (Brasil, 1992).

Nos tratamentos onde se utilizou o papel como substrato, no SP as sementes foram distribuídas sobre duas folhas de papel mata-borrão previamente umedecidas com quantidade de água equivalente a 2,3 vezes a massa do substrato e no RP as sementes foram distribuídas sobre duas folhas de papel toalha "germitest", cobertas com mais uma folha de papel e enroladas; nesse caso as folhas de papel foram umedecidas com quantidade de água equivalente a 2,5 vezes a massa das mesmas.

O teste de avaliação da sensibilidade das sementes à luz para a germinação foi conduzido em germinador, a $25^{\circ} \mathrm{C}$, com oito repetições de 25 sementes por tratamento utilizando-se o substrato vermiculita (EV e SV), em duas condições, na presença e na ausência de luz. Na primeira condição foram seguidos os procedimentos descritos anteriormente para o estudo de substratos; já para a condição de ausência de luz, as caixas plásticas foram mantidas no interior de bandejas plásticas $(45 \mathrm{~cm} \times 30 \mathrm{~cm} \times 10 \mathrm{~cm})$ envoltas com papel alumínio, como objetivo de evitar a incidência de luz nas sementes.
Em ambos os estudos as sementes e as plântulas foram avaliadas diariamente, até a estabilização da germinação das sementes, considerando-se como plântula normal as que tinham as estruturas essenciais do embrião desenvolvidas. As avaliações de percentagens e índices de velocidade de germinação na ausência de luz foram realizadas sob luz verde. Com os dados obtidos nas avaliações, foram calculados os índices de velocidade de germinação (IVG), de acordo com a fórmula descrita por Maguire (1962), e as percentagens de germinação.

Concomitantemente às avaliações, foram registrados diferentes estádios do processo de germinação, plântulas normais, anormais e sementes mortas, por meio de câmera fotográfica digital Nikon, modelo D1.

Foi utilizado para o experimento um delineamento inteiramente casualizado. Para execução da análise, foi utilizado o Sistema de Análise Estatística para Microcomputadores - SANEST (Zonta e Machado, 1984), e para a análise da variância, os dados em percentagem foram transformados em arc sen da raiz quadrada de $\mathrm{x} / 100$ e as médias comparadas pelo teste de Tukey, a 5\% de probabilidade de erro.

\section{RESULTADOS E DISCUSSÃO}

As sementes utilizadas na pesquisa apresentaram teor de água de $9,9 \%$ e massa de 1000 sementes de $14,8 \mathrm{~g}$. A semente (Figura 1), plântula normal (Figura 2) e a anormalidade mais freqüente em plântulas (Figura 3) estão apresentados na seqüência.

\section{FIGURA 1. Semente de Parapiptadenia rigida (angico vermelho).}

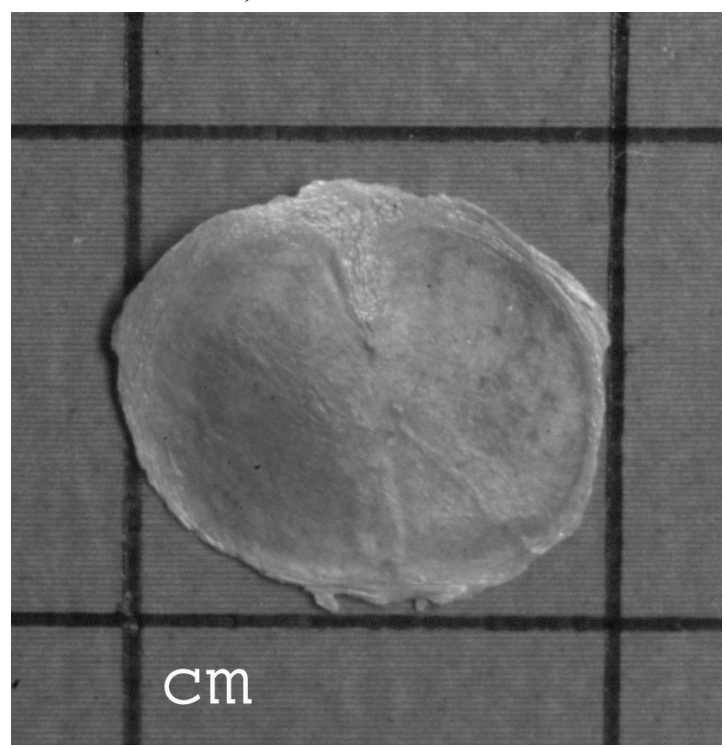


FIGURA 2. Plântula normal de Parapiptadenia rigida (angico vermelho).

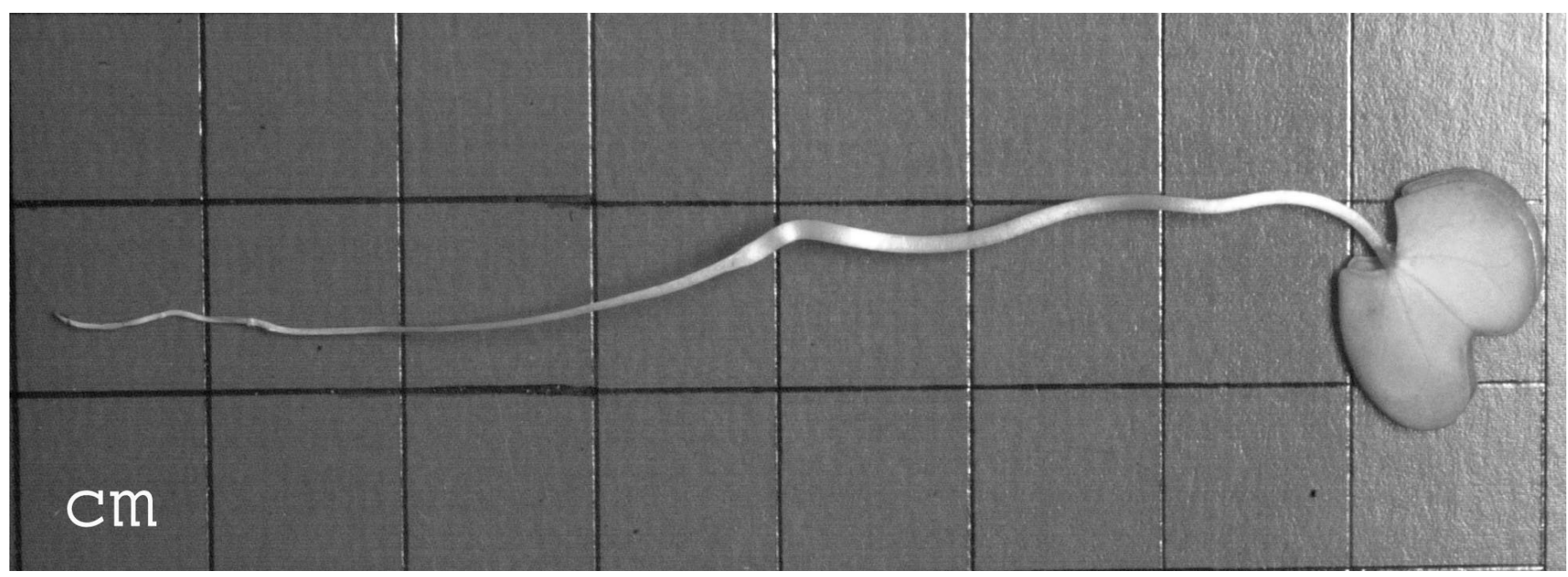

FIGURA 3. Anormalidade mais freqüente em plântulas de Parapiptadenia rigida (angico vermelho).

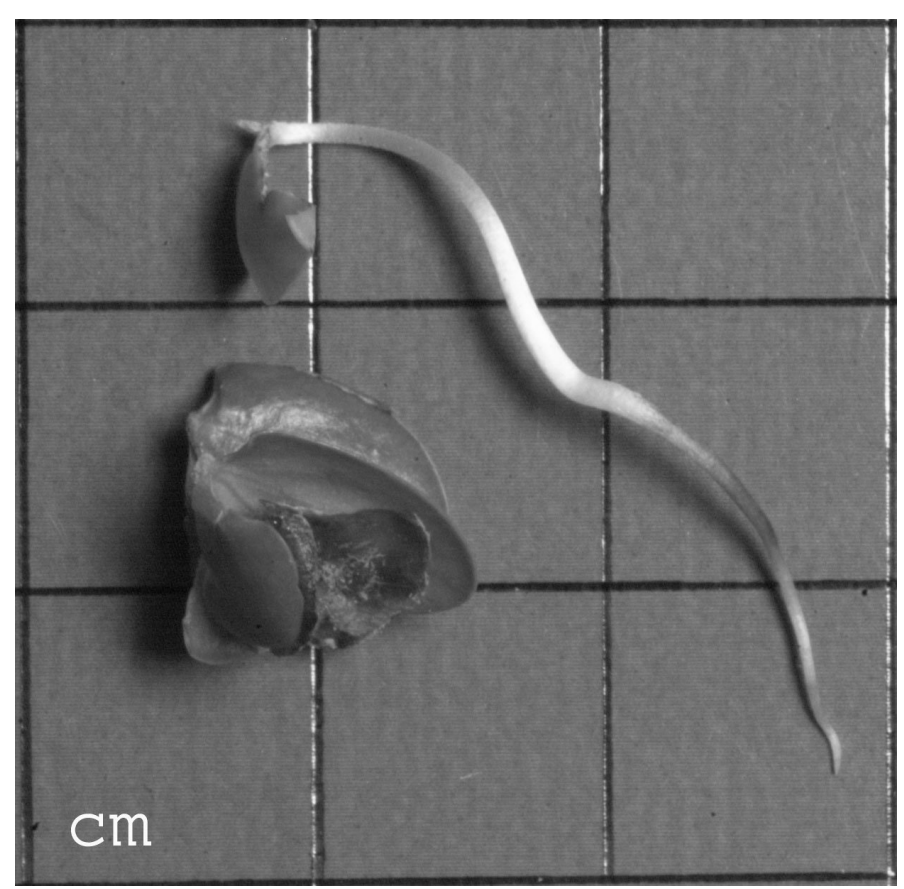

Os resultados referentes ao estudo do efeito da temperatura (Tabela 1) indicaram que as maiores percentagens e os maiores índices de velocidade de germinação foram obtidos no intervalo entre $23,7^{\circ} \mathrm{C}$ e $32,4^{\circ} \mathrm{C}$, sob temperaturas constantes, correspondentes aos tratamentos T5 a T8. Observou-se, também, que temperaturas constantes inferiores a $19,4^{\circ} \mathrm{C}$ inibem o processo germinativo, sugerindo que essa temperatura é a mínima para a ocorrência da germinação dessa espécie (Carvalho e Nakagawa, 2000); no entanto, por meio dos resultados não foi encontrada uma temperatura máxima para a inibição da germinação das sementes dessa espécie, porém, o IVG decresceu acima da temperatura de $32,4^{\circ} \mathrm{C}$.

TABELA 1. Germinação (G) e índice de velocidade de germinação (IVG) de sementes de angico vermelho, em nove intervalos de temperaturas (IT).

\begin{tabular}{ccc}
\hline IT $\left({ }^{\circ} \mathrm{C}\right)$ & G $(\%)$ & IVG $(\%)$ \\
$32,5-35,0$ & $70 a b^{*}$ & $12,09 \mathrm{~b}$ \\
$30,3-32,4$ & $91 \mathrm{a}$ & $16,85 \mathrm{a}$ \\
$28,1-30,2$ & $93 \mathrm{a}$ & $18,25 \mathrm{a}$ \\
$25,9-28,0$ & $88 \mathrm{a}$ & $18,15 \mathrm{a}$ \\
$23,7-25,8$ & $92 \mathrm{a}$ & $14,77 \mathrm{ab}$ \\
$21,6-23,6$ & $52 \mathrm{bc}$ & $5,09 \mathrm{c}$ \\
$19,4-21,5$ & $29 \mathrm{c}$ & $2,64 \mathrm{~cd}$ \\
$17,2-19,3$ & $0 \mathrm{~d}$ & $0 \mathrm{~d}$ \\
$15,0-17,1$ & $0 \mathrm{~d}$ & $0 \mathrm{~d}$ \\
\hline $\mathrm{CV}(\%)$ & 18,96 & 20,00 \\
\hline
\end{tabular}

*Na coluna, médias seguidas pela mesma letra, não diferem entre si, pelo teste de Tukey, a $5 \%$ de probabilidade de erro.

Com base nos resultados desse estudo, nas informações disponíveis em literatura para sementes dessa 
espécie (Alcalay e Amaral, 1981; Ramos et al., 1995; Figliolia et al., 2005) e, também, nas temperaturas comumente utilizadas em germinadores de laboratórios de análise de sementes, foram selecionadas as temperaturas $25^{\circ} \mathrm{C}$ e $30^{\circ} \mathrm{C}$ para a realização do estudo de substratos.

Os resultados relativos ao estudo de substrato (Tabela 2) indicaram que a germinação das sementes nos tratamentos $\mathrm{EV}, \mathrm{SV}$ e $\mathrm{SP}$, na temperatura de $25^{\circ} \mathrm{C}$, foram semelhantes. Porém, analisando os dados referentes ao IVG, os tratamentos EV, SV e RP na temperatura de $25^{\circ} \mathrm{C}$ apresentaram desempenhos semelhantes entre si e superior ao tratamento SP. Interações significativas entre substrato e temperatura foram relatadas por Figliola et al. (1993) e Santos e Aguiar (2000), corroborando os resultados do presente trabalho.

TABELA 2. Germinação (G) e índice de velocidade de germinação (IVG) de sementes de angico vermelho, em diferentes substratos e temperaturas.

\begin{tabular}{cll}
\hline Tratamento & G $(\%)$ & IVG $(\%)$ \\
\hline EV $25^{\circ} \mathrm{C}^{*}$ & $96 \mathrm{a} * *$ & $19,15 \mathrm{a}$ \\
$\mathrm{EV} 30^{\circ} \mathrm{C}$ & $70 \mathrm{~b}$ & $13,05 \mathrm{~b}$ \\
$\mathrm{SV} 25^{\circ} \mathrm{C}$ & $82 \mathrm{ab}$ & $14,99 \mathrm{ab}$ \\
$\mathrm{SV} 30^{\circ} \mathrm{C}$ & $74 \mathrm{~b}$ & $13,04 \mathrm{~b}$ \\
$\mathrm{SP} 25^{\circ} \mathrm{C}$ & $86 \mathrm{ab}$ & $11,77 \mathrm{~b}$ \\
$\mathrm{SP} 30^{\circ} \mathrm{C}$ & $79 \mathrm{~b}$ & $12,06 \mathrm{~b}$ \\
$\mathrm{RP} 25^{\circ} \mathrm{C}$ & $71 \mathrm{~b}$ & $15,4 \mathrm{ab}$ \\
$\mathrm{RP} 30^{\circ} \mathrm{C}$ & $64 \mathrm{~b}$ & $14,67 \mathrm{~b}$ \\
\hline $\mathrm{CV}(\%)$ & 15,98 & 19,75 \\
\hline
\end{tabular}

*EV - entre vermiculita; $\mathbf{S V}$ - sobre vermiculita; $\mathbf{S P}$ - sobre papel; RP Rolo de papel.

**Na coluna, médias seguidas pela mesma letra, não diferem entre si, pelo teste de Tukey, a $5 \%$ de probabilidade de erro.

No entanto, Figliolia et al. (2005), realizando a aferição de testes de germinação de sementes florestais nativas, utilizaram como padrão para o teste de germinação das sementes de angico vermelho a condição sobre papel a $25^{\circ} \mathrm{C}$. Embora no presente trabalho a temperatura de $25^{\circ} \mathrm{C}$ tenha se mostrado como a mais adequada para o teste de germinação dessas sementes, conforme também observado por Alcalay e Amaral (1981), o mesmo não foi observado para a condição sobre papel, já que a velocidade de germinação foi inferior a dos demais substratos.

De acordo com Ramos et al. (1995), o teste de germinação das sementes de angico vermelho pode ser conduzido com os substratos vermiculita, areia, papel mata-borrão e papel toalha, nas temperaturas de $20^{\circ} \mathrm{C}$ e de $25^{\circ} \mathrm{C}$, resultados que divergem em parte dos obtidos no presente trabalho, já que apenas o substrato vermiculita, a $25^{\circ} \mathrm{C}$, foi a melhor condição para o teste.

Assim, os melhores resultados encontrados, avaliando-se a interação temperatura e substrato, foram com a utilização do substrato vermiculita, utilizando-se os tratamentos EV e $\mathrm{SV}$ na temperatura de $25^{\circ} \mathrm{C}$. Segundo Piña Rodrigues e Vieira (1988) e Figliola et al. (1993), a vermiculita vem sendo utilizada com bons resultados para as sementes de espécies florestais, principalmente devido a sua boa capacidade de absorção e retenção de água.

Dessa forma, para o estudo de sensibilidade à luz, foram selecionados os substratos EV e SV na temperatura de $25^{\circ} \mathrm{C}$. Quando comparados os tratamentos EV com luz e EV sem luz (Tabela 3), observa-se que a percentagem e o índice de velocidade de germinação dos tratamentos não diferiram entre si, da mesma forma quando são comparados os tratamentos SV com luz e SV sem luz, confirmando que as sementes realmente apresentam um comportamento não fotoblástico, ou seja, a presença ou a ausência de luz não afeta o processo germinativo das sementes. Em contrapartida aos resultados encontrados, a importância da presença de luz para a germinação das sementes de espécies florestais tem sido freqüentemente relatada (Queiroz, 1982; Orozco Segovia e Vázquez Yanes, 1989; Andrade, 1995; Válio e Scarpa, 2001; Godoi e Takaki, 2004; Godoi e Takaki, 2005).

TABELA 3. Germinação (G) e índice de velocidade de germinação (IVG) de sementes de angico vermelho e o efeito da luz para os tratamentos entre e sobre vermiculita.

\begin{tabular}{cll}
\hline Tratamento & G $(\%)$ & IVG $(\%)$ \\
\hline EV Sem Luz* & $91 \mathrm{a} * *$ & $13,75 \mathrm{a}$ \\
EV Com Luz & $80 \mathrm{ab}$ & $12,50 \mathrm{ab}$ \\
SV Com Luz & $75 \mathrm{~b}$ & $10,50 \mathrm{bc}$ \\
SV Sem Luz & $69 \mathrm{~b}$ & $8,63 \mathrm{c}$ \\
\hline CV $(\%)$ & 13,41 & 15,57 \\
\hline
\end{tabular}

*EV - entre vermiculita; $\mathbf{S V}$ - sobre vermiculita.

**Na coluna, médias seguidas pela mesma letra, não diferem entre si, pelo teste de Tukey, a 5\% de probabilidade de erro. 
Entretanto, quando se fez a comparação conjunta dos tratamentos desse estudo (Tabela 3) observou-se que os tratamentos EV com luz e EV sem luz apresentaram percentagem e índice de velocidade de germinação superiores aos demais. O tratamento SV sem luz foi inferior aos tratamentos $\mathrm{EV}$, sugerindo que este não deva ser utilizado para a condução do teste de germinação. Nesse caso a interação do substrato com a ausência de luz foi prejudicial à germinação das sementes.

Deve-se destacar que o substrato EV permitiu o desenvolvimento adequado das plântulas, principalmente quanto ao suporte físico, ao contrário do tratamento SV. Além disso, o maior contato das sementes com o substrato facilitou a liberação do tegumento, propiciando o desenvolvimento mais rápido da plântula.

\section{CONCLUSÃO}

O teste de germinação para as sementes de Parapiptadenia rigida (angico vermelho) deve ser conduzido na temperatura de $25^{\circ} \mathrm{C}$, utilizando-se o substrato entre vermiculita, na presença ou na ausência de luz.

\section{REFERÊNCIAS}

ALCALAY, N.; AMARAL, D.M.I. Determinação de métodos de análise de espécies florestais que não constam nas Regras para Análise de Sementes. Roessléria, Porto Alegre, v.4, n.1, p.75-83, 1981.

ANDRADE, A.C.S. Efeito da luz e da temperatura na germinação de Leandra breviflora Cogn., Tibouchina benthamiana Cogn., Tibouchina grandifolia Cogn. e Tibouchina moricandiana (DC.) Baill. (Melastomataceae). Revista Brasileira de Sementes, Brasília, v.17, n.1, p.29$35,1995$.

ANDRADE, A.C.S.; SOUZA, A.F.; RAMOS, F.N.; PEREIRA, T.S.; CRUZ, A.P.M. Germinação de sementes de jenipapo: temperatura, substrato e morfologia do desenvolvimento pós-seminal. Pesquisa Agropecuária Brasileira, Brasília, v.35, n.3, p.609-615, 2000.

BRASIL, Ministério da Agricultura e Reforma Agrária. Regras para análise de sementes. Brasília: SNDA/DNDV/ CLAV, 1992, 365p.

CARVALHO, N.M.; NAKAGAWA, J. Sementes: ciência, tecnologia e produção. 4.ed. Jaboticabal: FUNEP, 2000, $588 \mathrm{p}$.

DURIGAN, G.; NOGUEIRA, J.C.B. Recomposição de matas ciliares. São Paulo: Instituto Florestal, (IF. Série
Registros, 4), 1990, 14p.

FIGLIOLIA, M.B.; OLIVEIRA, E.C.; PIÑA RODRIGUES, F.C.M. Análise de sementes. In: AGUIAR, I.B.; PIÑA RODRIGUES, F.C.M.; FIGLIOLIA, M.B. (Coord.). Sementes florestais tropicais. Brasília: ABRATES, p.137174, 1993.

FIGLIOLIA, M.B.; MARTINS, L.; NOVEMBRE, A.D.L.C.; CHAMMA, H.M.C.P.; PIÑA RODRIGUES, F.C.M. Aferição de testes de germinação de sementes florestais nativas. Informativo ABRATES, Brasília, v.15, n.1,2,3, p.327, 2005.

GODOI, S.; TAKAKI, M. Effects of light and temperature on seed germination in Cecropiahololeuca Micq.(Cecropiaceae). Brazilian Archives of Biology and Technology, Curitiba, v. 47, p. 185-191, 2004.

GODOI, S.; TAKAKI, M. Efeito da temperatura e a participação do fitocromo no controle da germinação de sementes de embaúba. Revista Brasileira de Sementes, Brasília, v.27, n.2, p.87-90, 2005.

GOMES, S.M.S.; BRUNO, R.L. Influência da temperatura e substratos na germinação de sementes de urucum (Bixa orellana L.). Revista Brasileira de Sementes, Brasília, v.14, n.1, p.47-50, 1992.

LOPES, J.C.; SOARES, A.S. Germinação de sementes de Miconia cinnamomifolia (Dc.) Naud. Brasil Florestal, Brasília, n.75, p.31-39, 2003.

LORENZI, H. Árvores brasileiras: manual de identificação e cultivo de plantas arbóreas do Brasil. $4^{\mathrm{a}}$ ed. Nova Odessa: Instituto Plantarum, v.1, 2002, 368p.

MARCOS FILHO, J. Germinação de sementes. In: SEMANA DE ATUALIZAÇÃO EM PRODUÇÃO DE SEMENTES, 1. Piracicaba, 1986. Campinas: Fundação Cargill, 1986, p.11-39.

MAGUIRE, J.D. Speeds of germination-aid selection and evaluation for seedling emergence and vigor. Crop Science, Madison, v.2, p.176-177, 1962.

MAYER, A.C.; POLJAKOFF MAYBER, A. The germination of seeds. $4^{\text {th }}$ ed. Oxford: Pergamon Press, 1989, 270 p.

NASSIF, S.M.L.; PEREZ, S.C.J.G. Efeitos da temperatura na germinação de sementes de amendoim-do-campo (Pterogyne nitens Tul.). Revista Brasileira de Sementes, Brasília, v. 22, n.1, p.1-6, 2000.

OROZCO SEGOVIA, A.; VÁZQUEZ YANES, C. Light effect on seed germination in Piper L. Ecologia Plantarum, Londres, v.10, p.123-146, 1989. 
PIÑA RODRIGUES, F.C.M.; VIEIRA, J.D. Teste de germinação. In: PIÑA RODRIGUES, F.C.M. Manual de Análise de Sementes Florestais. Campinas: Fundação Cargill, 1988, 100p.

POPINIGIS, F. Fisiologia da semente. Brasília: AGIPLAN, 1985, 289p.

QUEIROZ, M.H. Aspectos preliminares de beneficiamento e germinação de Miconia cinnamomifolia. Silvicultura em São Paulo, São Paulo, v.16, p.318-321, 1982.

REITZ, R.; KLEIN, R. M.; REIS, A. Projeto madeira do Rio Grande do Sul. Porto Alegre, Herbário Barbosa RodriguesH.B.R.; Superintendência do desenvolvimento da Região Sul-SUDESUL; Secretaria da Agricultura e AbastecimentoDRNR, 1988, 525 p.

RAMOS, A.; BIANCHETTI, A.; MARTINS, E.G.; FOWLER, J.A.P.; ALVES, V.F. Substratos e temperaturas para a germinação de sementes de angico (Parapiptadenia rigida). Colombo: EMBRAPA-CNPF, (EMBRAPA-CNPF. Comunicado Técnico, 3), 1995, 1p.

SAKITA, M.N.; VALLILO, M.I. Estudos fitoquímicos preliminares em espécies florestais do Parque Estadual do Morro do Diabo, Estado de São Paulo. Revista do Instituto Florestal, São Paulo, v.2, n.2, p.215-226, 1990.

SANTOS, S.R.G.; AGUIAR, I.B. Germinação de sementes de branquilho Sebastiania commersoniana (Baill.) Smith \& Downs) em função do substrato e do regime de temperatura. Revista Brasileira de Sementes, Brasília, v.22, n.1, p.120126, 2000.

SILVA, M.C. Efeito da temperatura na germinação de sementes de manduirana (Senna macranthera (Collad.) Irwin et Barn. - Caesalpiniaceae). Revista Brasileira de Sementes, Brasília, v. 23, n.1, p.92-99, 2001.

SILVA, L.M.M.; RODRIGUES, T.J.D.; AGUIAR, B.A.
Efeito da luz e da temperatura na germinação de sementes de aroeira (Myracrodruon urundeuva Allemão). Revista Árvore, Viçosa, v.26, n.6, 2002.

SOUSA, M.P.S.; BRAGA, L.F.; BRAGA, J.F.; SÁ, M.E.; MORAES, M.L.T. Influência da temperatura na germinação de sementes de sumaúma (Ceiba pentranda (Linn.) Gaertn. - Bombacaceae). Revista Brasileira de Sementes, Brasília, v.22, n.1, p.110-119, 2000.

SOUTO, J.J.P. Deserto, uma ameaça? Estudos dos núcleos de desertificação na fronteira sudoeste do Rio Grande do Sul. Porto Alegre: Secretaria da Agricultura - Departamento de Recursos Naturais Renováveis, 1984, 169p.

VACCARO, S.; LONGHI, S.J.; BRENA, D.A. Aspectos da composição florística e categorias sucessionais do estrato arbóreo de três subseres de uma floresta estacional decidual, no Município de Santa Tereza - RS. Ciência Florestal, Santa Maria, v.9, n.1, p.1-18, 1999.

VÁLIO, I.F.M.; SCARPA, F.M. Germination of seeds of tropical pioneer species under controlled and natural conditions. Revista Brasileira de Botânica, São Paulo, v. 24, p. 79-84, 2001.

VARELA, V.P.; FERRAZ, I.D.K.; CARNEIRO, N.B. Efeito da temperatura na germinação de sementes de sumaúma (Ceiba pentandra L.Gaertn. - Bombacaceae). Revista Brasileira de Sementes, Brasília, v.21, n.2, p.170-174, 1999.

VILLIERS, T.A. Seed dormancy. In: KOZLOWSKI, T.T. (ed.). Seed biology. New York: Academic Press, 1972, p.219-281.

ZONTA, E.P.; MACHADO, A.A. Sistema de análise estatística para microcomputadores-SANEST. Pelotas, 1984, 109p. 